\title{
Title:
}

\section{Superior mesenteric vein aneurysm}

\section{Authors:}

José López-Fernández, Gabriel García Plaza, Sara María García Quesada, Juan Ramón Hernández Hernández

DOI: $10.17235 /$ reed.2021.7932/2021

Link: PubMed (Epub ahead of print)

Please cite this article as:

López-Fernández José, García Plaza Gabriel, García Quesada Sara María, Hernández Hernández Juan Ramón. Superior mesenteric vein aneurysm. Rev Esp Enferm Dig 2021. doi: 10.17235/reed.2021.7932/2021.

This is a PDF file of an unedited manuscript that has been accepted for publication. As a service to our customers we are providing this early version of the manuscript. The manuscript will undergo copyediting, typesetting, and review of the resulting proof before it is published in its final form. Please note that during the production process errors may be discovered which could affect the content, and all legal disclaimers that apply to the journal pertain. 


\section{IPD 7932 inglés}

\section{Superior mesenteric vein aneurysm}

José López-Fernández ${ }^{1}$, Gabriel García Plaza ${ }^{1}$, Sara María García Quesada² and Juan Ramón Hernández Hernández ${ }^{1}$

Departments of ${ }^{1}$ General and Digestive Surgery and ${ }^{2}$ Radiodiagnosis. Hospital Universitario Insular Materno-Infantil. Las Palmas de Gran Canaria, Spain

Received: $17 / 12 / 2020$

Accepted: $29 / 12 / 2020$

Correspondence: José López-Fernández

e-mail: jlopezfdez89@gmail.com

\section{CASE REPORT}

A 41-year-old female patient was under study for abdominal pain located in the epigastrium and mesogastrium with no other associated symptoms. There was no record of previous episodes of pancreatitis and she denied abdominal trauma and laboratory tests were normal. A computed tomography (CT) scan was performed (Figs. 1 and 2) showing an aneurysm of the superior mesenteric vein, varicose veins in the gastrohepatic ligament and a left splenorenal shunt. The study was completed with upper gastrointestinal endoscopy with no pathological findings, and the measurement of the portosystemic pressure gradient was $4 \mathrm{mmHg}$. The liver biopsy was reported as F2 fibrosis and SAF score $(2,2,2)$. Annual radiological follow-up was decided.

\section{DISCUSSION}

Superior mesenteric vein aneurysm is an extremely rare radiological finding, with just over a dozen reported cases. It usually presents as mild abdominal pain in the right upper quadrant, although it may also manifest as bleeding (1) or compression of the extrahepatic bile duct (2). They can be congenital or acquired in origin. In the case of congenital aneurysms, they are due to aberrant development of the vitelline veins 
during the embryonic period. The cause of acquired aneurysms is unclear, but could be secondary to liver cirrhosis, portal hypertension, pancreatitis or abdominal trauma (3). Surgical treatment has been proposed as a therapeutic option, especially in patients with underlying liver pathology and portal hypertension (2). However, due to the high morbidity and mortality that may be associated with such procedures, close radiological follow-up may be a recommended option, especially in patients with no associated risk factors.

\section{REFERENCES}

1. Wolosker N, Zerati AE, Nishinari K, et al. Aneurysm of superior mesenteric vein: case report with 5-year follow-up and review of the literature. J Vasc Surg 2004;39(2):459-61. DOI: 10.1016/j.jvs.2003.08.008

2. Fulcher A, Turner M. Aneurysms of the portal vein and superior mesenteric vein. Abdom Imaging 1997;22(3):287-92. DOI: 10.1007/s002619900191

3. Starikov A, Bartolotta RJ. Massive superior mesenteric venous aneurysm with portal venous thrombosis. Clin Imaging 2015;39(5):908-10. DOI: 10.1016/j.clinimag.2015.05.001 


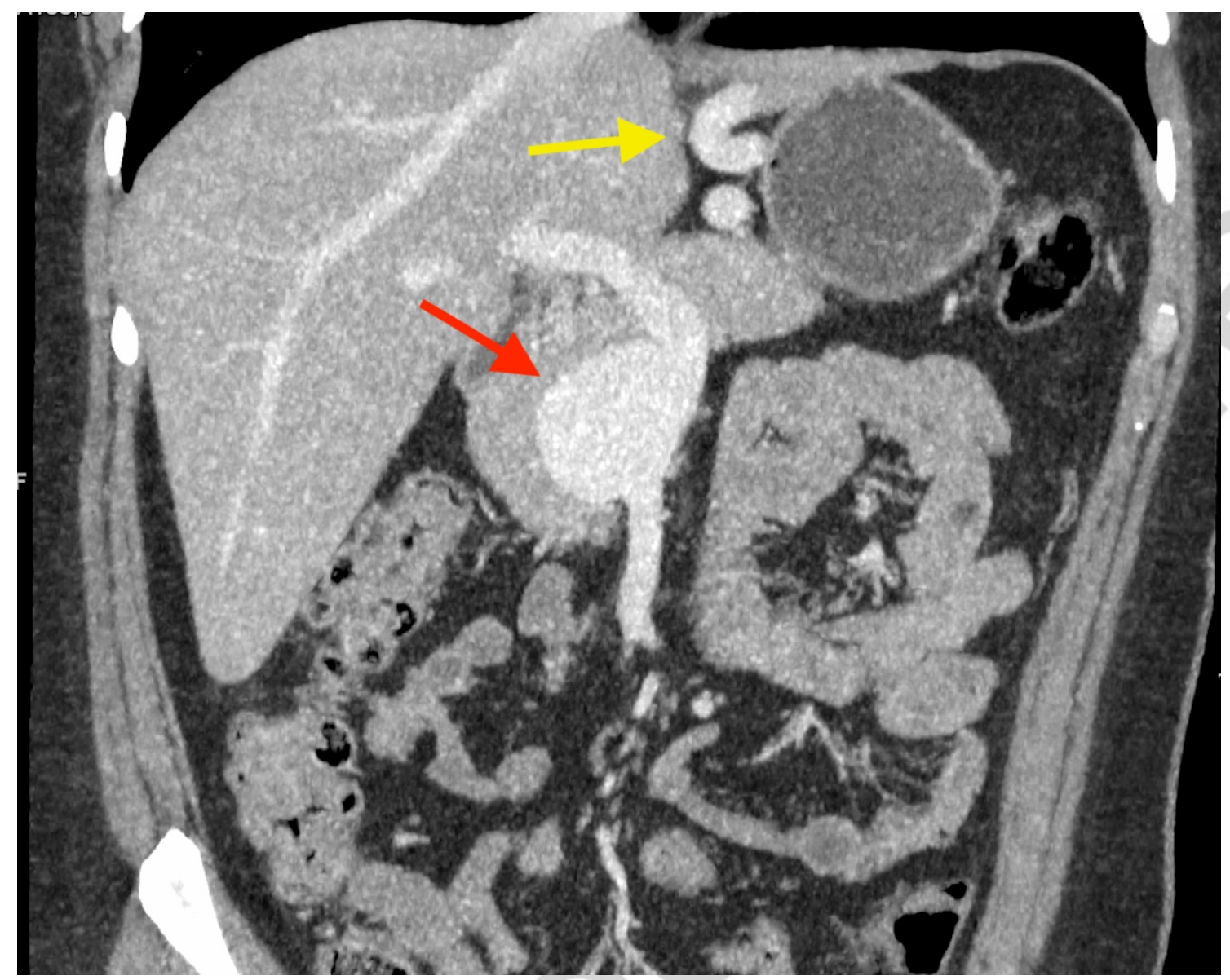

Fig. 1. Coronal CT image in venous phase. In the most proximal part of the superior mesenteric vein, immediately caudal to its junction with the splenic vein, there is an aneurysm of $43 \mathrm{~mm}$ in greatest diameter (red arrow). There is also a large varicose vein in the lesser gastric curvature (yellow arrow). 


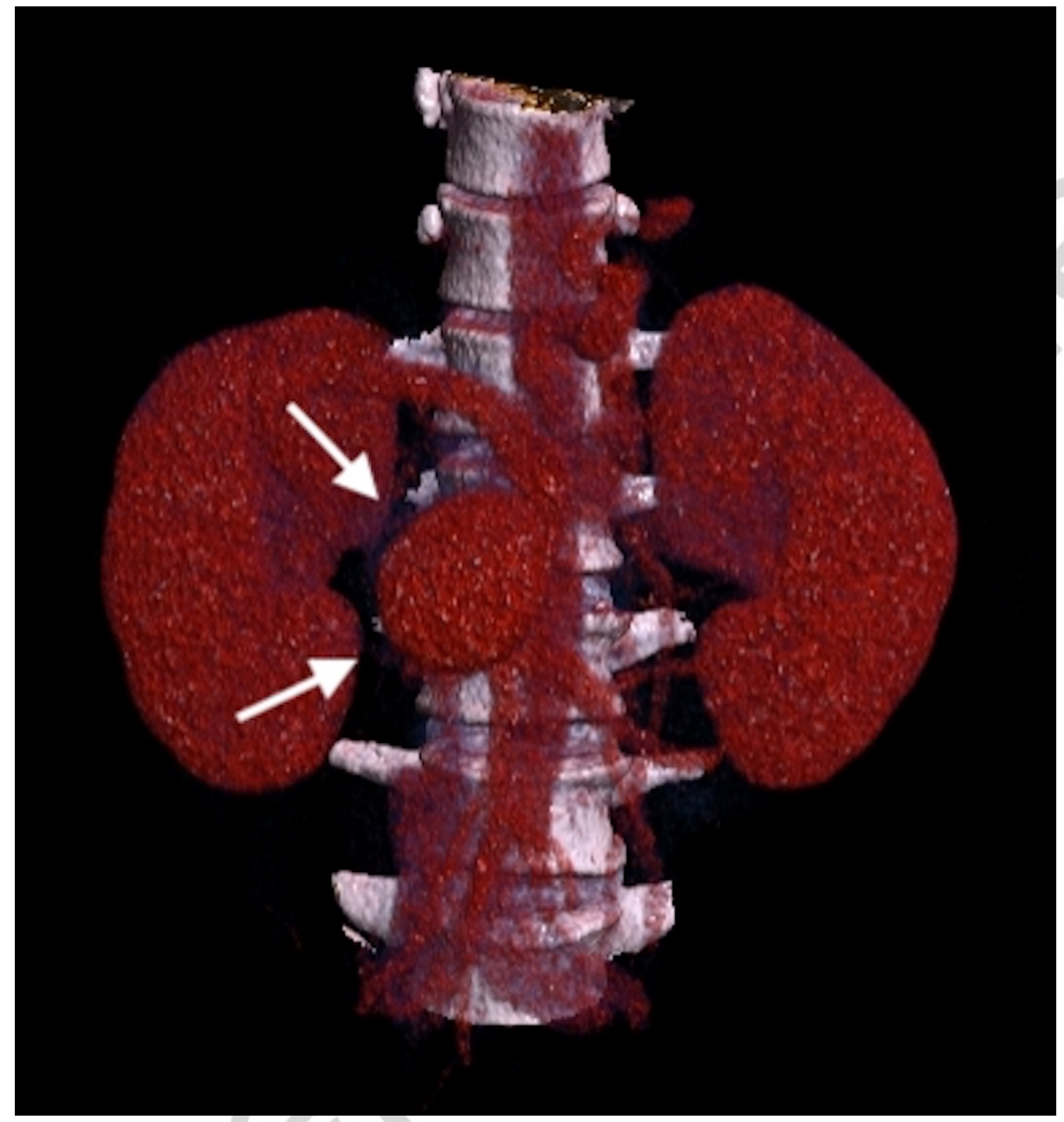

Fig. 2. Three-dimensional vascular reconstruction. The aneurysm (white arrows) and its relationship with the rest of the vascular structures can be seen. 